\title{
Evidence-based smoking cessation
}

\author{
A Sheikh
}

$\mathrm{C}$ laiming the lives of some four million people globally each year, smoking has been identified by the World Health Organisation as the most important preventable cause of avoidable mortality and morbidity in Western Europe. ${ }^{1}$ The British Government, in its recent White Paper, Smoking kills, identified smoking cessation as a national priority, and has outlined its wish to reduce the number of people smoking by 20,000 each year. ${ }^{2,3}$ It is recognised that success in achieving even such relatively modest targets will be crucially dependent on the support and co-operation of those working within primary care.

\section{EPIDEMIOLOGY AND DISEASE BURDEN}

There are about 13 million current smokers in the UK, the majority beginning the habit in adolescence. ${ }^{4}$ Factors predisposing to starting smoking include parental smoking, peer pressure and also advertising. Recent research has shown nicotine to be highly addictive, more so than even alcohol and cocaine, leading to nicotine addiction being classified as a disease in the International Classification of Diseases-10.5 A staggering 50\% of lifelong smokers will die prematurely as a direct consequence of their habit, the major causes of death being cancers and cardiovascular disease. ${ }^{4}$

Morbidity due to smoking costs the National Health Service approximately $£ 1.7$ billion each year, ${ }^{2}$ the health costs of caring for an individual smoker are typically up to $40 \%$ higher than the costs associated with caring for an equivalent non-smoker. However, if lost earnings through absences due to smokingrelated illness, decreased productivity associated with 'lighting-up time', and the health risks posed by passive smoking, are also taken into account, the full cost implications to society are far higher. ${ }^{6}$

\section{DO SMOKING CESSATION INTERVENTIONS WORK?}

Two-thirds of smokers are reported to wish that they could stop, and of these $50 \%$ (4.5 million) will make one or more attempts to do so each year. ${ }^{7}$ Yet success rates in those attempting to quit unaided remain disappointingly poor, with cessation being maintained for at least a year in only $3 \%$ of such attempts. ${ }^{8}$ The majority of those relapsing will do so within the first week, largely due to the symptoms associated with nicotine withdrawal.

\section{Behavioural advice}

A number of studies, conveniently summarised in a major systematic review by Law and Tang, have shown that brief physician advice and encouragement during a single routine consultation results in an improved cessation rate at one year post-advice of $2 \%$ (95\% CI $1-3, p<0.01$ ), over and above the $3 \%$ that manage to quit unaided. ${ }^{9}$ Such brief advice is particularly effective for smokers at higher than average risk of tobacco-related morbidity, such as

those with ischaemic heart disease and pregnant women. Supplementary interventions, in the form of follow-up visits and reminder letters, are likely to confer limited, if any, additional benefit. ${ }^{9,10}$ A fourstage approach to advice has been suggested: ${ }^{11}$

- $\quad$ Asking about smoking habits

- Advising smokers to stop

- Assisting those who want to stop

- Arranging appropriate follow-up.

Whilst government strategy is certainly correct in emphasising the importance of brief advice, many primary care workers are concerned about the suggestion that this advice should be given at 'each and every opportunity'. For example, a recent qualitative study which explored the factors influencing general practitioners' decisions to enter into discussions regarding smoking with their patients that smoked, revealed that doctors were concerned about indiscriminately discussing smoking for fear of damaging the doctor-patient relationship. Rather, they preferred to raise the subject as part of a problem-orientated management plan in those presenting with smoking-attributable morbidity, expressing the belief that it is in such cases that their advice was most likely to be appreciated and heeded. ${ }^{12}$

\section{Complementary therapies}

Advocates of complementary therapies have highlighted the high smoking cessation rates associated with techniques such as acupuncture, hypnotherapy and aversion therapy. However, many of the studies conducted to-date have been uncontrolled and are generally of poor quality. On the basis of systematic reviews of the efficacy of these interventions, none of these interventions can at present be recommended. ${ }^{13-15}$

\section{Pharmacological treatments}

There has been considerable commercial interest in finding effective pharmacological interventions that aid those wishing to stop smoking. A number of drug classes have been tested including anxiolytics, antidepressants, the antihypertensive clonidine, nicotine agonists, nicotine antagonists and nicotine replacement therapy.

Systematic review of the randomised controlled trial evidence for these treatments suggest that neither anxiolytics nor nicotine agonist therapy confer benefit. ${ }^{16,17}$ The limited data on the efficacy of nicotine antagonist therapy are somewhat more encouraging, particularly when combined with nicotine replacement therapy, but need to be verified in larger trials before routine use can be recommended. ${ }^{18}$ Clonidine also appears to improve cessation rates, the high incidence of side effects (dry mouth and sedation in the main), however, limiting its clinical usefulness. ${ }^{19}$ Results from trials assessing the efficacy of nicotine replacement therapy and antidepressants are more encouraging.
Aziz Sheikh

NHS R\&D National Primary Care Training Fellow

Correspondence to Department of General Practice and Primary Health Care, Imperial College School of Medicine, Norfolk Place, London W2 1PG, UK aziz.sheikh@ic.ac.uk

Date received: 13/07/00 Date accepted: 03/08/00 


\section{Nicotine replacement therapy}

Nicotine replacement therapy is designed to wean patients off nicotine through a controlled reduction in intake, thereby reducing nicotine withdrawal symptoms and the associated urge to recommence smoking. Preparations currently available include nicotine gum, transdermal patch, intranasal spray, sublingual therapy, inhaler and tablet. ${ }^{20}$ A systematic review of data from 49 trials found that the pooled odds ratio of success with treatment compared to control was 1.72 (95\% CI 1.60-1.84) at 6-12 months post-treatment, the different preparations having broadly similar efficacy, except in a subgroup of highly dependant smokers in whom high-dose gum therapy $(4 \mathrm{mg})$ was found to be significantly better than a lower dose $(2 \mathrm{mg})$. Eight weeks of patch therapy was found to be as effective as longer courses. There was no evidence that combination forms of nicotine replacement therapy conferred any additional benefit. ${ }^{21}$ Despite clear evidence in support of nicotine replacement therapy most preparations are currently blacklisted by the National Health Service; the only forms still licensed are some patches (Niquitin CQ), sublingual tablets (Nicorette microtab) and inhalers (Nicorette inhalator), though prescriptions for these items may be challenged by health authorities..$^{22,23}$

\section{Bupropion}

There is good evidence supporting the use of antidepressants in promoting cessation, the drugs so far tested including fluoxetine, moclobemide, nortriptyline and bupropion. ${ }^{16}$ Evidence is strongest for the novel antidepressant bupropion, ${ }^{24,25}$ which has recently been licensed for this use in the UK. ${ }^{26}$ Pooled results from the four trials to-date give a summary odds ratio for sustained cessation at 12 months compared with control of 2.73 (95\% CI 1.90-3.94). These benefits are dose dependent, the highest success rates achieved in those taking the maximum daily dose of $300 \mathrm{mg}$. Treatment is recommended for a maximum of nine weeks, a typical eight-week course of treatment costing the National Health Service approximately £86. Bupropion appears more effective than nicotine replacement patch therapy, and the combined treatment of bupropion and patch more effective than patch alone. ${ }^{25}$

The pharmacology of bupropion remains poorly understood; it is postulated that its mechanism of action is mediated through its dopaminergic and noradrenergic properties acting on the mesolimbic system which is involved in dependence. Bupropion has also been shown to have effects in the locus coeruleus, which mediates the symptoms of nicotine withdrawal. ${ }^{27}$ Side effects are generally mild, consisting mainly of dry mouth, gastrointestinal upset and insomnia. An unexpected benefit of treatment though is that the troublesome weight increase associated with cessation is very often reduced in those being treated with this agent.

\section{A STRATEGIC APPROACH TO SMOKING CESSATION}

The UK licensing of bupropion is a major advance in the battle against smoking-related morbidity and mortality. To ensure the maximum possible benefit is achieved, practices and primary care groups/trusts will need to develop a strategic approach to smoking cessation. In the absence of trial data comparing differing strategies, a two-step approach, beginning with the safest and most cost-effective intervention, seems prudent:

- Brief advice and review

- Pharmacological treatment

- Support and review.

\section{CONCLUSIONS}

Thanks largely to the very high-quality reviews undertaken by The Cochrane Tobacco Addiction Group, we now have a good understanding of the interventions that are most likely to confer benefit in the important battle against smoking addiction. Central to all treatment strategies is the need for brief professional advice, reminding patients of the benefits associated with stopping smoking, the nicotine withdrawal effects that they should expect, reassurance that such withdrawal symptoms are usually short-lived, information about sources of support, and a commitment to review progress at 6-12 months post advice. Clinical experience and common sense suggest that such advice is most likely to be positively received if offered to the very many patients that will consult with smoking-related morbidity in the context of a problem-orientated management plan.

Success can be considerably enhanced if this advice is combined with either nicotine replacement therapy or bupropion, though the former may not be available on National Health Service prescription in all areas. It is salutary to remember that helping an individual to stop smoking remains one of the most cost-effective interventions that we as clinicians can make. ${ }^{28}$

\section{Acknowledgements}

The author is supported by a NHS R\&D National Primary Care Training Fellowship.

\section{References}

1. Asvall JE. The WHO wants governments to encourage people to stop smoking. BMJ 1997;314:1688

2. Department of Health. Smoking kills: A white paper on tobacco. London: Her Majesty's Stationery Office; 1998

3. NHS Executive. Health Service Circular: New NHS smoking cessation services. London: NHSE; 1999

4, Royal College of Physicians. Nicotine addiction in Britain. London: RCP; 2000

5. World Health Organisation. International statistical classification of diseases and related health problems (ICD10). Geneva: WHO; 1992

6. Cohen D, Barton G. The cost to society of smoking cessation. Thorax 1998;53 (Suppl 5):S38-42

7. Thomas M, Walker A, Wilmot A, et al. Living in Britain: Results from the 1996 General Household Survey. London: The Stationery Office; 1998

8. Arnsten JH. Treatment of nicotine dependence in the primary care setting. Prim Psych 1996;3:27-30

9. Law M, Tang MJ. An analysis of the effectiveness of interventions intended to help people stop smoking. Arch Int Med 1995; 155:1933-41

10. Lancaster T, Dobbie W, Vos K, et al. Randomised trial of nurse-assisted strategies for smoking cessation in primary care. Br J Gen Pract 1999;49:486

11. Manley MW, Epps RP, Glynn TJ. The clinician's role in promoting smoking cessation among clinic patients. Med Clin N Amer 1992;76:477-94

12. Coleman T, Murphy E, Cheater F. Factors influencing discussions of smoking between general practitioners and patients who smoke: A qualitative study. Br J Gen Pract 2000;50:207-10 
13. White AR, Rampes H, Ernst E. Acupuncture for smoking cessation (Cochrane Review). In: The Cochrane Library, Issue 2, 2000. Oxford: Update Software; 2000

14. Abbot NC, Stead LF, White AR, et al. Hypnotherapy for smoking cessation (Cochrane Review). In: The Cochrane Library, Issue 2, 2000. Oxford: Update Software; 2000

15. Hajek P, Stead LF. Aversive smoking for smoking cessation (Cochrane Review). In: The Cochrane Library, Issue 2, 2000. Oxford: Update Software; 2000

16. Hughes JR, Stead LF, Lancaster T. Anxiolytics and antidepressants for smoking cessation (Cochrane Review). In: The Cochrane Library, Issue 2, 2000. Oxford: Update Software; 2000

17. Stead LF, Hughes JR. Lobeline for smoking cessation (Cochrane Review). In: The Cochrane Library, Issue 2, 2000. Oxford: Update Software; 2000

18. Lancaster T, Stead LF. Mecamylamine (a nicotine antagonist) for smoking cessation (Cochrane Review). In: The Cochrane Library, Issue 2, 2000. Oxford: Update Software; 2000

19. Gourlay SG, Stead LF, Benowitz NL. Clonidine for smoking cessation (Cochrane Review). In: The Cochrane Library, Issue 2, 2000. Oxford: Update Software; 2000

20. Anon. Nicotine replacement therapy to aid smoking cessation. Drug Ther Bull 1999:37:52-4

21. Silagy C, Mant D, Fowler G, et al. Nicotine replacement therapy for smoking cessation (Cochrane Review). In: The Cochrane Library, Issue 2, 2000. Oxford: Update Software; 2000

22. Duncan C (ed). Monthly index of medical specialities. London: Haymarket Medical Ltd, July 2000: 354

23. Smeeth L, Fowler G. Nicotine replacement therapy for a healthier nation. BMJ 1998;317:1266-7

24. Hurt RD, Sachs DL, Glover ED, et al. A comparison of sustained-release bupropion and placebo for smoking cessation. N Engl J Med 1997;337:1195-202

25. Jorenby DE, Leischow SJ, Nides MA, et al. A controlled trial of sustained-release bupropion, a nicotine patch, or both for smoking cessation. $N$ Engl J Med 1999;340:685-91

26. Britton J, Jarvis MJ. Bupropion: A new treatment for smokers. BMJ 2000;321:65-6

27. Ascher JA, Cole JO, Colin NJ, et al. Bupropion: A review of its mechanism of antidepressant activity. J Clin Psychiatry 1995;56:395-401

28. Parrot S, Godfrey C, Raw M, et al. Guidance for commissioners on the cost effectiveness of smoking cessation interventions. Thorax 1998;53 (Suppl 5):S1-38 